\title{
Modified Ovate Pontic Design for Immediate Anterior Tooth Replacement
}

\author{
Swapnali Mhatre, Anita Gala, Sabita M Ram, Naisargi Shah
}

\begin{abstract}
Pontic is an artificial substitute for the missing tooth. The design of this prosthetic tooth will be dictated by esthetics, functions, hygiene, patient comfort and maintenance of the edentulous ridge. An ovate pontic has been widely recommended to fulfill both esthetic and functional requirements of the prosthesis. The convex design of this pontic intends to form a concave soft tissue outline at the site of the alveolar ridge mucosa. This design eliminates the 'black triangle' which is created after loss of tooth and interdental papilla. Clinically, healthy conditions can be established at pontic site, if appropriate plaque control is performed.

Unfortunately, an ovate pontic design is not frequently advised by the clinicians. The case report presented a modified ovate pontic design for replacing upper anterior tooth to give both esthetics and health.
\end{abstract}

Keywords: Esthetic restoration, Modified ovate pontic.

How to cite this article: Mhatre S, Gala A, Ram SM, Shah N. Modified Ovate Pontic Design for Immediate Anterior Tooth Replacement. J Contemp Dent 2012;2(2):64-68.

\section{Source of support Nil}

Conflict of interest: None declared

\section{INTRODUCTION}

One of the most challenging issues in a dental treatment is to preserve interproximal soft tissue and to avoid alveolar bone from collapse after the extraction of a tooth. It is important to preserve the socket size, shape and the space of the gingival tissue in order to maintain the tissue height and fill the extracted site with the provisional pontic immediately. The shape and form of a pontic is not the only important criteria to be taken into account for the good outcome, the contours of the gingival tissue are also an important factor. Pontic should support the gingival contours and eliminate the 'black triangle'.

Historically, different types of pontic design have been used in anterior region like the saddle, the ridge lap, the modified ridge lap and the ovate pontics. The saddle pontic enhanced esthetics, but due to its design, covering the ridge made flossing difficult leading to poor hygiene maintenance; the ridge lap pontic was designed to overcome the draw backs of the saddle pontic, but could not be used for all types of ridge contours. ${ }^{1}$ They further underwent modification making them more self-cleansing with reduction of the lingual surface to form the modified ridge lap, but these pontic were uncomfortable to the tongue and brought about food entrapment on the lingual side and phonetic difficulties due to escape of air and saliva from the lingual surface.

Dewey and Zugsmith ${ }^{2}$ advocated the ovate pontic way back in 1933 for achieving optimal esthetic after extraction. It was created with a convex shape on the tissue surface to overcome the disadvantages of the ridge lap and modified ridge lap pontics. The convex shape of the ovate pontic helps to create and maintain the presence of interdental papilla, more accurately duplicate emergence profile and maintain hygiene in subpontic area. ${ }^{3-6}$ The ovate pontic contacted a larger area of the underlying soft tissue and applied pressure on the ridge tissue, in contrast with the ridge lap or modified ridge lap pontics, which were only in contact with tissue without appliction of pressure. ${ }^{3}$ Ovate pontics can be used in posterior or anterior quadrants with equal success. However, esthetic demands are more in the anterior quadrant so it can be highly recommended in the anterior region.

The ovate pontic had a draw back that it needed sufficient faciolingual width and apicocoronal height to incorporate the pontic within the edentulous ridge. It was generally contraindicated for the thin, knife-edge residual ridge. A surgical augmentation procedure was required when the faciolingual and apicoincisal dimensions are inadequate. ${ }^{7}$

Chiun-Lin Steven Liu ${ }^{8}$ improvises the design of ovate pontic for enhancing the esthetic and maintenance of hygiene by moving the height of contour of the pontic more labially to support the soft tissue and get the required emergence profile (Fig. 1). The tissue surface of the modified pontic was less convex than the surface of the ovate pontic. This was called the modified ovate pontic which does not require as much faciolingual thickness to create an emergence profile. The less convex design of the modified ovate pontic allowed it to be cleansed easily compared to the ovate pontic.

This article describes a technique for placing the modified ovate pontics immediately after extraction of a tooth to preserve the soft and hard tissues for enhancing esthetics.

\section{CASE REPORT}

A 25-year-old male patient reported to Department of Prosthodontics with chief complaint of a broken anterior 
tooth for which he desired replacement for enhancing esthetic. On examination, it was observed that maxillary right central incisor (21) was grossly carious and fractured partially below cementoenamel junction (CEJ) level. Radiograph showed a short carious rootstump which was not amenable for a post and core restoration (Fig. 2).

The patient was informed regarding the condition of 21 and no possibility of saving it for post and core restoration. The option of implant and fixed partial denture was also given to the patient. The patient opted for tooth supported fixed partial denture. To enhance the esthetic of this anterior restoration and for immediate replacement, fixed partial denture with modified ovate pontic was finally planned.

Diagnostic impressions were made; mock preparation and diagnostic wax up was done for case evaluation (Fig. 3). Putty index in silicon was made with help of wax up to guide tooth preparation and provisionalization. Tooth preparation to recieve a compl ete ceramometal fixed partial denture was carried out for 11 and 22 as abutment teeth with rounded shoulder finish line ${ }^{9}$ (Fig. 4). A n irreversible

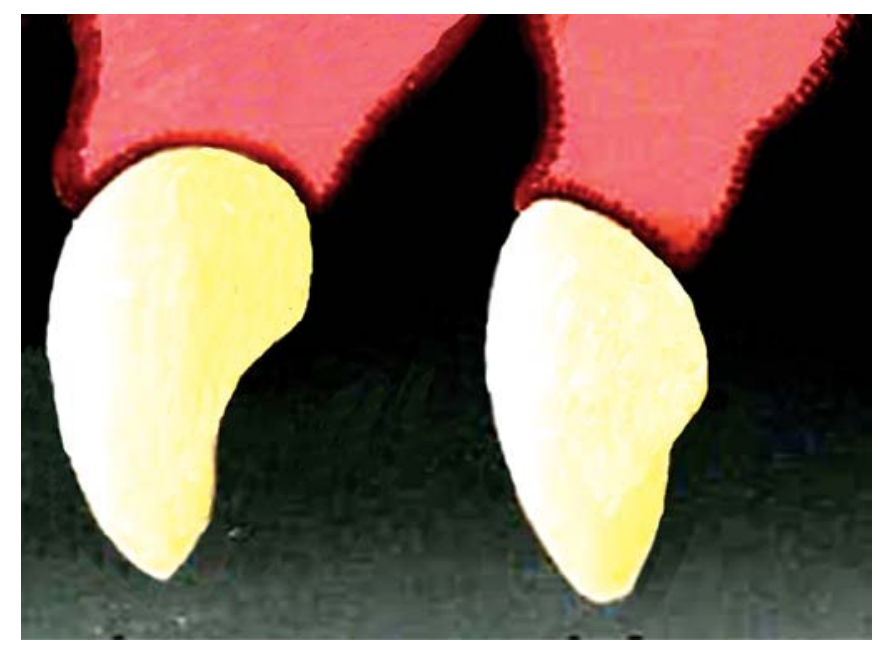

Fig. 1: Ovate and modified ovate pontic

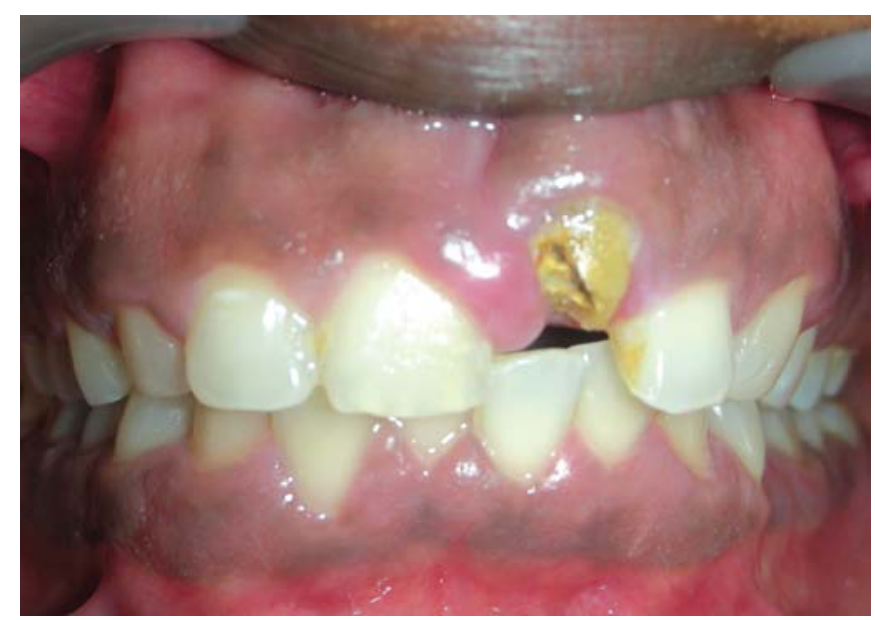

Fig. 2: Preoperative intraoral hydrocolloid impression of the prepared teeth and future extraction site was made.

Cast was made to evaluate the space for modified ovate pontic. Scraping the cast was carried out at the future extraction site for the modified ovate pontic (Fig. 5). A pical length/depth of pontic decided according to level of CEJ and interproximal bone level on intraoral periapical (IOPA). Provisional bridge was fabricated in tooth-colored heatcured acrylic resin by the indirect technique using the putty index (Fig. 6). Tissue surface of the pontic was kept highly polished so that irritation to tissue and plaque accumulation can be avoided.

Extraction of (21) root was done with help of microtome to preserve buccal and lingual plates and interdental papilla. After hemostasis and clot formation modified ovate pontic was adjusted to 3 to $4 \mathrm{~mm}$ into the socket to support the bone and soft tissue contour. As it was modified ovate pontic, it was more labially placed on ridge than ovate pontic. Cementation of the provisional restoration was done with help of eugenol-free interim luting agent (Fig. 7).

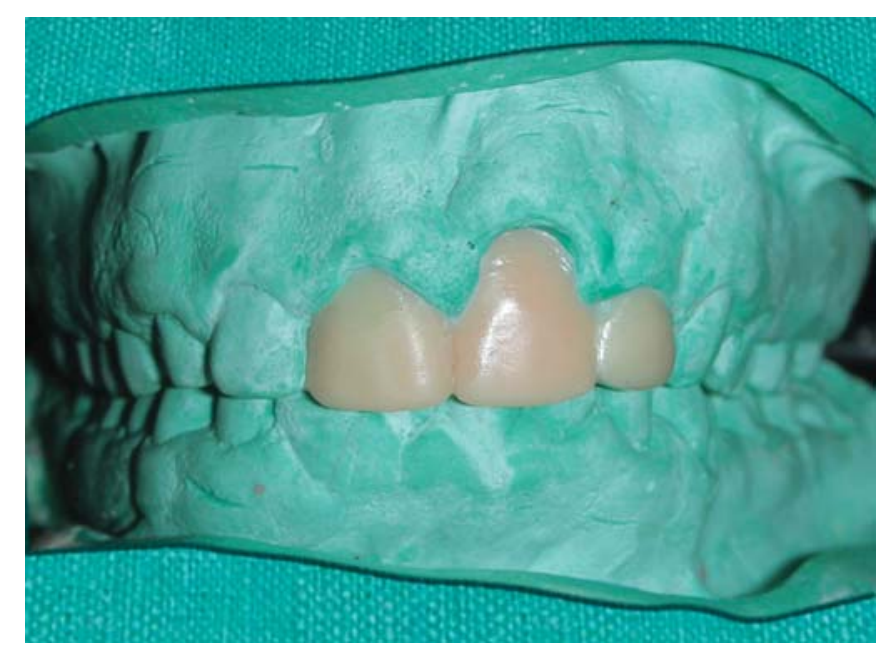

Fig. 3: Diagnostic wax up

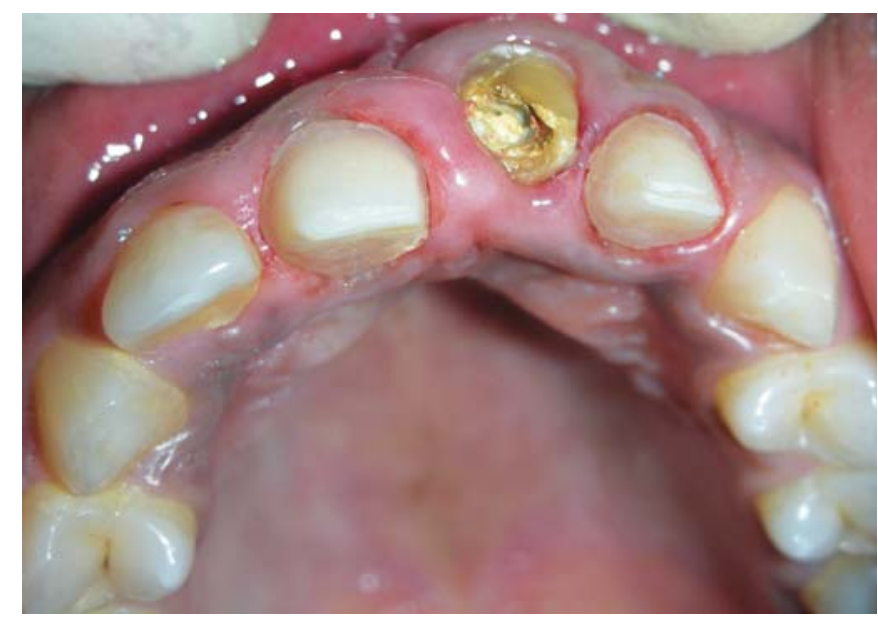

Fig. 4: Tooth preparation of abutment (11 and 22) 
Extraction and immediate placement of the provisional restoration would allow the soft tissue to be supported by ovate pontic. Crown lengthening was carried out in the 3 rd week after extraction. This was necessary to get the proper height of contour and proportion of gingival contour for esthetic. The preparation was modified to compensate tissue shrinkage and to maintain the finish line subgingivally for the esthetic. The provisional restoration was refined to ensure marginal fit and contour.

The tissue condition both at the abutment teeth and the pontic were monitored after 1 week, 1 and 3 months (Figs 8 and 9). In each recall, appointment health of soft tissue was assessed by removing the provisional restoration, checking the ovate pontic sight for absence of ulceration or extravasations of blood vessels. Pink healthy tissue and minimal tissue rebound was expected. At each visit, the modified ovate pontic was polished on the tissue surface.

Final tooth preparation and final impression were made to receive full coverage metal ceramic restoration after a

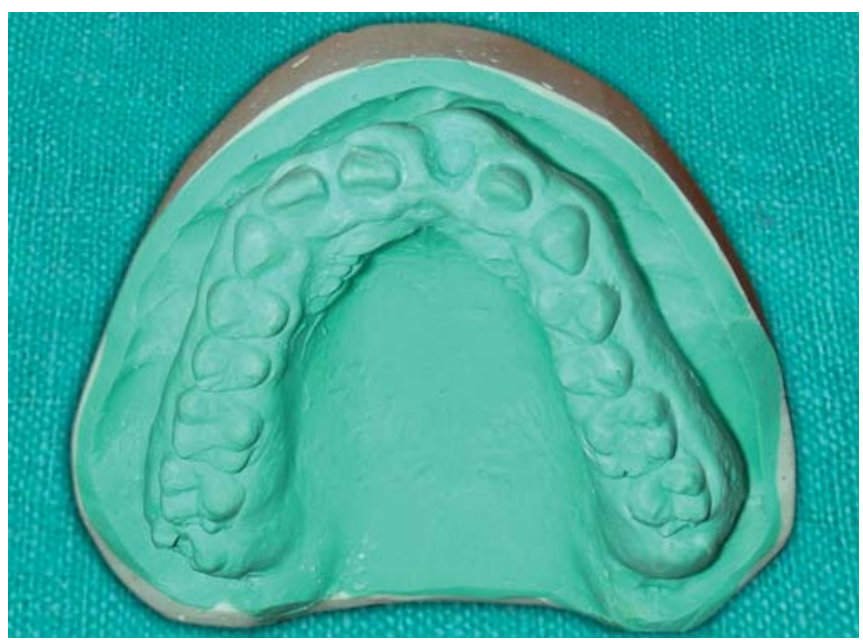

Fig. 5: Preparation of future extraction site to receive ovate pontic on cast

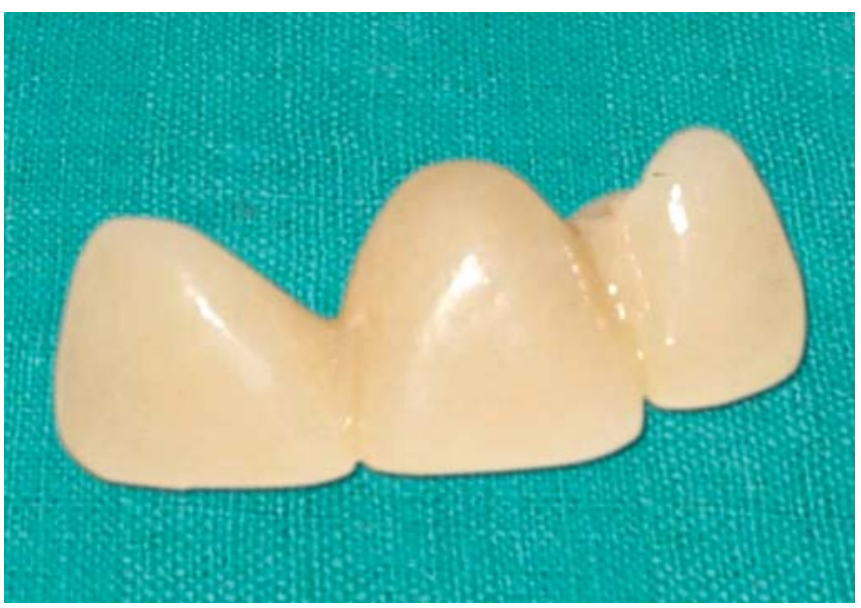

Fig. 6: Heat cure acrylic provisional restoration with modified ovate pontic time interval of 3 months. When healing is complete, minor modification of tooth preparation is necessary because of tissue shrinkage. Die was prepared and a 3 unit ceramometal bridge was fabricated (Figs 10 and 11). The metal ceramic

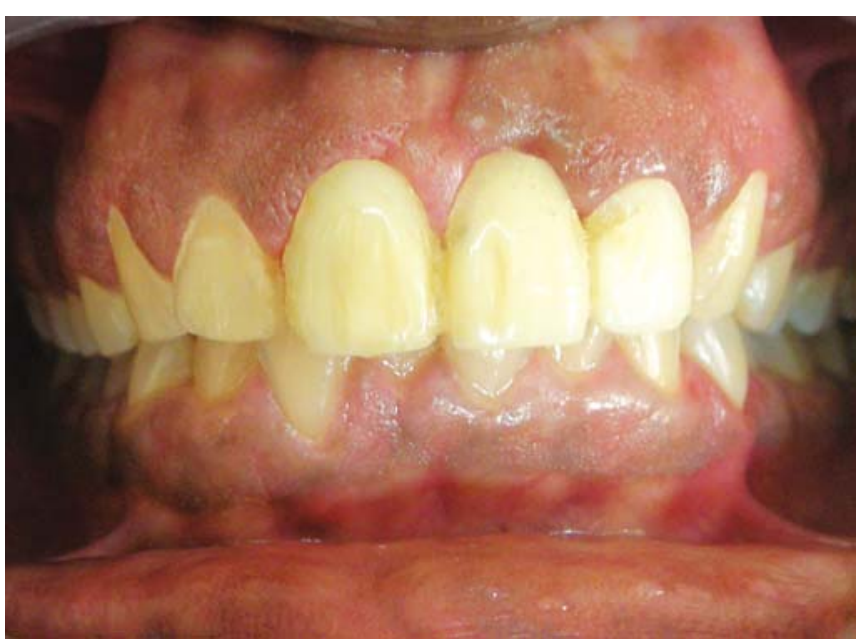

Fig. 7: Provisional restoration in situ

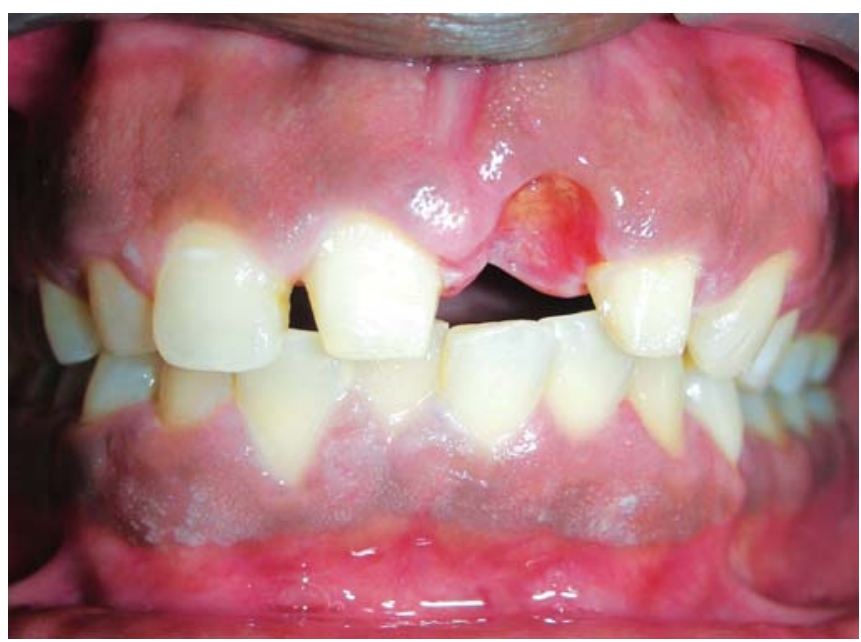

Fig. 8: Healing after 3-week postextraction

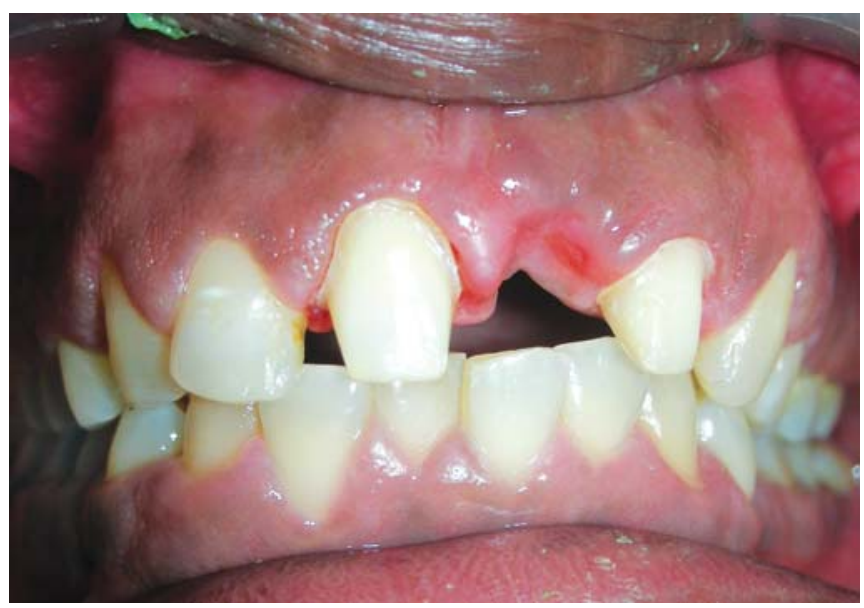

Fig. 9: Healing after 3-month postextraction 
Modified Ovate Pontic Design for Immediate Anterior Tooth Replacement

bridge was fabricated with highly glazed ceramic at the tissue surface of the pontic. Controlled physiologic pressure was used at the pontic site to enhance the interdental papilla and create the illusion of pontics emerging from the soft tissue, thus creating a natural-looking effect of the restoration of the pontic of the replaced central incisor.

\section{DISCUSSION}

This article presents a rationale for selection of modified ovate pontic as an alternative to traditional pontic forms for anterior tooth replacement. Literature has shown that the use of other types of anterior pontic designs have not always been based on scientific data. ${ }^{9} \mathrm{~A}$ method for the fabrication of an acceptable ovate pontic before extraction is described here. If precise attention to detail is given, predictable final results with good esthetics can be consistently accomplished.

When tooth extraction is inevitable, it should be extracted carefully to protect lateral papillae and buccal/ lingual plates. With help of modified ovate pontic tissue and bone contours can be controlled and preserved to give naturally appearing emergence profile to the prosthesis. Ease of cleaning is technically easier in these types of pontic. The other advantage of modified ovate pontic is lateral tissue support and food deflection. ${ }^{10}$ The axial contours of the pontic form a deflection ridge to prevent food impaction, yet remain subtle enough to provide a massaging action to the gingival.

However, some patients may not accept teeth to be prepared adjacent to lost tooth and treatment may be timeconsuming. Detailed attention to the provisional restoration is necessary for an acceptable marginal fit. It is important that final impressions for the fixed partial denture (FPD) should be made immediately after removal of the provisional restoration or tissue may 'rebound' and create an ovate pontic space on the model substantially shallower than the

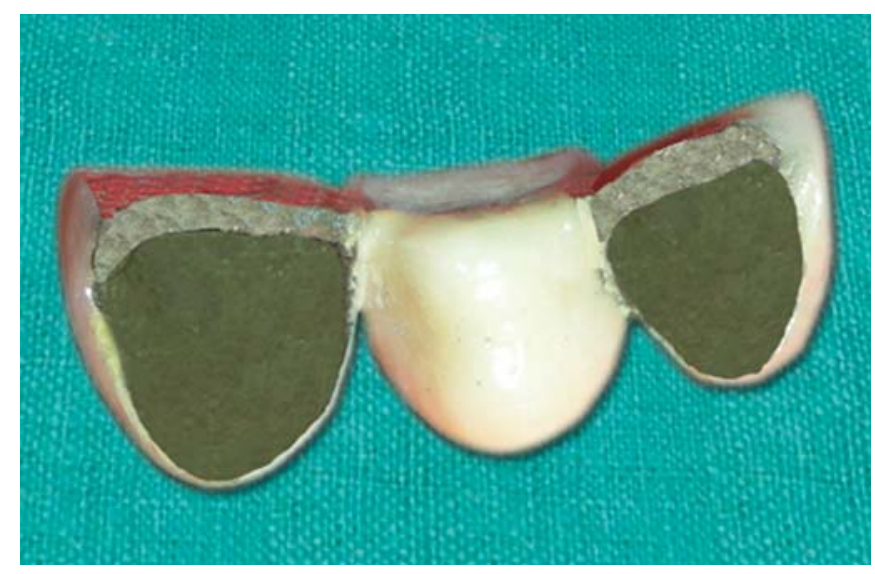

Fig. 10: Intaglio surface of final prosthesis showing modified ovate pontic actual provisional pontic. ${ }^{9}$ This can result in an inaccurate relationship between pontic and tissue surface.

A pical pontic height was determined by the existing tissue/bone complex, esthetics, support, ease of cleaning and prevention of food impaction. Passive ridge contact was indicated for most pontic forms ${ }^{11}$ but the ovate pontic requires intimate contact to support, form and protect tissue. M inimal alveolar bone loss was observed while remodelling after extraction as no tissue incisions were made. There are numerous articles that advocate a passive ridge contact for pontics. ${ }^{2,12}$ The recent data and experience have indicated that active contact may be better. The stimulation of active contact al ong with the occlusal forces could enhance tissue tone and health. However, if flossing the areas of hyperpressure does not take place, inflammation is unavoidable. ${ }^{13}$

Replacement of acrylic resin provisional restoration with metal ceramic definitive fixed partial denture was chosen due to the importance of esthetics in this highly visible area. The tissue was al ready conditioned by the contours of the tissue side of the interim fixed partial denture, there was no space between the definitive fixed partial denture and gingiva. The fixed partial denture blended in beautifully with the natural teeth with good esthetic and no black triangles.

\section{SUMMARY}

A technique was described involving use of a modified ovate pontic to replace missing anterior tooth and a nonsurgical approach for the management of soft tissue contour. A historical and biological perspective has been presented for the use of the modified ovate pontic. Controlled pressure was used on the pontic site to enhance the interdental papilla and create the illusion of pontic emerging from the soft tissue, thus creating a natural-looking effect of the restoration. Final success of prosthesis will rest with the oral hygiene practices of the patient.

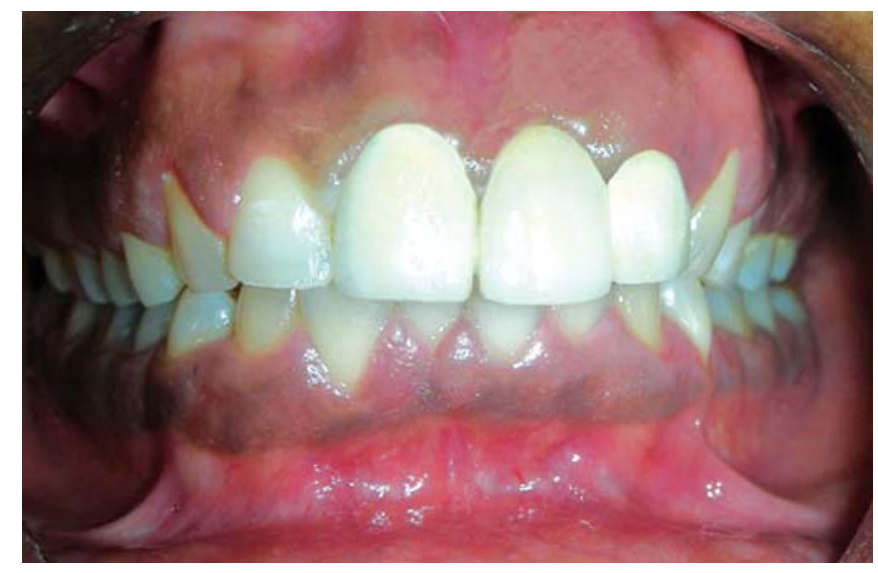

Fig. 11: Final metal ceramic fixed partial denture in situ 


\section{REFERENCES}

1. Stein RS. Pontic-residual ridge relationship: A research report. J Prosthet Dent 1966;16:251-85.

2. Dewey KW, Zugsmith R. A n experimental study of tissue reactions about porcelain roots. J D ent Res 1933;13:459-72.

3. M iller M B. A esthetic anterior reconstruction using a combined periodontal/restorative approach. Pract Periodontics A esthet Dent 1993;5:33-40.

4. Winter RR. Esthetic pontics. Dent Econ 1994;84:92-93.

5. Garber DA, Rosenberg ES. The edentulous ridge in fixed prosthodontics. Compend Contin Educ D ent 1981;2:212-23.

6. Johnson GK, Leary JM. Pontic design and localized ridge augmentation in fixed partial denture design. Dent $\mathrm{Clin} N$ orth A m 1992;36:591-605.

7. A brams L. A ugmentation of the deformed residual edentulous ridge for fixed prosthesis. Compend Contin Educ Gen Dent 1980;1:205-13.

8. Liu C-LS. Use of a modified ovate pontic in areas of ridge defects: A report of two cases. J Esthet Restor Dent 2004 ;16:27383.

9. Dylina TJ, M erced. Contour determination for ovate pontics calif. J Prosthet Dent 1999;82:136-42.

10. Kim TH, Cascione D, Knezevic A. Simulated tissue using a unique pontic design: A clinical report. J ProsthetD ent 2009;102: 205-10.

11. Tarantola GJ, Becker IM. D efinitive diagnostic waxing with light-cured composite resin. J Prosthet Dent 1993;70:315-19.
12. Council on dental materials and devices. Pontics in fixed prostheses status report. J Am D ent A ssoc 1975;91:613-17.

13. Tripodakis AP, Constantinides A. Tissue response under hyperpressure from convex pontics. Int J Periodontics Restorative Dent 1990;10:408-14.

\section{ABOUT THE AUTHORS}

\section{Swapnali Mhatre (Corresponding Author)}

Senior L ecturer, Department of Prosthodontics, M GM Dental College and Hospital, Navi Mumbai, Maharashtra, India e-mail: dr.swapnali.m@gmail.com

\section{Anita Gala}

Senior Lecturer, Department of Prosthodontics, M GM Dental College and Hospital, Navi M umbai, M aharashtra, India

\section{Sabita M Ram}

Dean, Professor and Head, Department of Prosthodontics, M GM Dental College and Hospital, Navi M umbai, M aharashtra, India

\section{Naisargi Shah}

Professor, Department of Prosthodontics, M GM Dental College and Hospital, Navi M umbai, M aharashtra, India 